Thorax, 1977, 32, 281-286

\title{
Respiratory health and dust levels in cottonseed mills
}

\author{
R. N. JONES, J. CARR, H. GLINDMEYER, J. DIEM, AND H. WEILL \\ From the Pulmonary Diseases Section, Tulane University, New Orleans, Louisiana, USA
}

Jones, R. N., Carr, J., Glindmeyer, H., Diem, J., and Weill, H. (1977). Thorax, 32, 281-286. Respiratory health and dust levels in cottonseed mills. Four cottonseed mills in the southern United States contained high levels of total and respirable dust. A survey of 172 workers showed low prevalences of byssinosis $(2 \cdot 3 \%)$ and chronic bronchitis (4\%). Mean baseline (out of dust) lung function values were normal. Mean functional declines over the working shift were present on Monday and absent on Friday, indicating an acute bronchoconstrictor response. Despite limitations in translating measured dust levels into estimates of individual exposures, the overall dose-response relationship seems to differ from that found in the cotton textile industry.

Byssinosis may result from inhaling any of several vegetable fibres under a variety of occupational exposures. The cotton textile industry has been the locus of most of the systematic studies of the disease. Non-textile exposures to cotton dust have received little attention, probably because these operations are predominantly rural, dispersed, and seasonal, and have a high turnover of unskilled labour.

As a result of the morbidity and disability from byssinosis in textile workers, governments have undertaken to regulate the permissible exposure to cotton dust. The major task is to define a safe and feasible limit of exposure. It is reasonable also to consider whether to apply the same standard to all sources of airborne cotton dust. The answer to this question should depend upon whether byssinosis is found in non-textile workers, and whether the dust-dose biologic-response relationship is similar to that in the textile industry.

Cottonseed is an important product of cotton cultivation. Seed mills separate the raw cottonseed into 'linters' (attached short cotton fibres), hulls, and meats, the last being the source of oil and cake or meal. The early steps in processing involve removal of coarse trash by mechanical shakers, stripping the linters from hulls by revolving saws, and collecting the baling linters. These operations raise substantial amounts of dust. The cottonseed is not treated in any way before it reaches the mill.

\section{Study population and methods}

In the summer of 1975 , we studied workers in four cottonseed mills in the southern United States. We attempted to recruit all workers in dusty jobs and a number of other cottonseed mill workers (thought to be only minimally exposed to dust) to serve as a comparison group. In three mills, we recruited as many workers as were willing to participate. In the fourth and largest mill, all workers in dusty jobs were recruited, and as many with minimal exposures as study time permitted. One hundred and seventy-two workers completed the interview; 153 completed function studies for inclusion in the Monday analysis (reasons for exclusion included having less than 40 hours off work before testing, or unexpected absence from work). Of these 153 workers, 145 were available for study on Friday of the same week.

Frequency distributions of the ages and length of employment in this population are shown in Figure 1. The age distribution is bimodal with a mean age of 40.5 years. The distribution of length of employment is skewed, $32 \%$ working for two or fewer years in these mills. Of the 153 men completing tests on Monday, $30 \%$ were non-smokers and $70 \%$ were smokers or ex-smokers. Based on job categories, 69 men were thought to have high, continuous dust exposure, 53 were assigned to an intermediate exposure group, and 31 were con- 


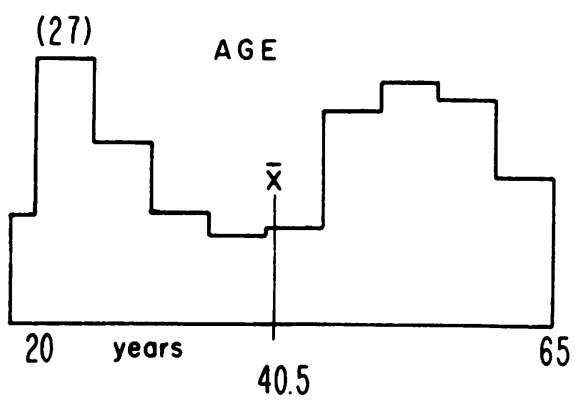

(54)

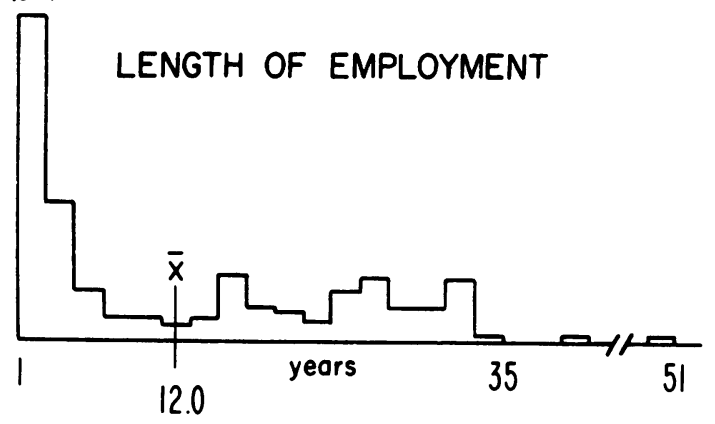

Fig. 1 Study population $(N=172)$.

sidered to have minimal exposures. These assignments were based on observations of time spent in dusty areas, and were made because worker mobility prevented translation of area dust measurements into personal exposure levels. Dust measurements were made at the time of interviewing and lung function testing in each mill. Area samples were obtained using vertical elutriators that collected dust particles of less than $15 \mu \mathrm{m}$ diameter. Total dust levels, obtained using personal monitors, were used to estimate exposures of persons who divided their time between several areas, or who worked in areas that could not be monitored with the vertical elutriator.

A trained interviewer administered a questionnaire containing standardised items about respiratory health and byssinosis. Byssinosis was defined as chest tightness, or cough, phlegm, or difficult breathing, occurring (or worsening) on the first day back at work after an absence of $\mathbf{4 0}$ or more hours. 'Chronic byssinosis' was defined by a past history of the symptoms defining byssinosis and a current history of lower respiratory symptoms. 'Chronic bronchitis' was defined by cough and phlegm on most days for three or more consecutive months, in two or more consecutive years. 'Dyspnoea' was considered present if the subject was breathless when hurrying on the level or walking up a slight hill, or on less exertion? 'Lengthy exposure' was defined as working more than five years in these mills.

Ventilatory function measurements were obㅇํㅇ tained using an electronic dry rolling-seal spiros meter. Testing was done before work and after a $\vec{b}$ least five hours' work on Monday and Friday of the same week. The measurements obtained were్ based on five maximum forced expirations dis played on volume-time and flow-volume plots. Pre dicted values for each subject took into account age, height, and race. Changes in flow rates ovefw the working shift were calculated using an iso 0 volume technique.

Analysis of results was directed toward deter? mining the effects of three potential influencing variables: level of dust exposure (high, inter mediate, or minimal); length of dust exposure ('lengthy', as defined above, or 'short'); ande smoking.

\section{Results}

ENVIRONMENTAL MEASUREMENTS

A summary of results of dust sampling is provided in Table 1. The number of samples making up the mean and median values is highly variable, ranging from three to about 20. A number of area and personal dust levels are quite high, especially in mill III. In general, the elutriated samples show levels considerably higher than the $0.2 \mathrm{mg} / \mathrm{m}: \frac{\mathrm{O}}{2}$ standard proposed by the National Institute forx Occupational Safety and Health (NIOSH) for textile mills, and in fact higher than the levels already attained by many textile mills.

\section{SYMPTOMS}

Three individuals fulfilled the criteria for 'byssino $\frac{D}{8}$ sis', giving histories of a Monday pattern of respiratory symptoms. One of these was a youngo man who answered yes to almost every question $\mathrm{He}$ had been employed only one year in a job with minimal dust exposure, and was a non- $-\omega$ smoker. Although he was counted as havinge byssinosis, his answers were considered to be ofe doubtful veracity. He also failed to show a decline⿻ in forced expiratory volume in one second $\left(\mathrm{FEV}_{1}\right)_{\bar{T}}^{-}$ over the working shift, although his isovolume forced expiratory flow over $25-75 \%$ of forced vitali capacity $\left(\mathrm{FEF}_{25-75}\right)$ declined by $0.351 / \mathrm{sec}$. The other two participants fitting this definition were both smokers and were in the intermediate expo sure category. One had short and the other hado lengthy employment, the former showed a decline 
Table 1 Dust levels

\begin{tabular}{|c|c|c|c|c|c|c|c|}
\hline & \multicolumn{4}{|c|}{$\begin{array}{l}\text { Area samples } \\
\text { Elutriated dust }\left(\mathrm{mg} / \mathrm{m}^{8}\right)\end{array}$} & \multicolumn{3}{|c|}{$\begin{array}{l}\text { Personal samples } \\
\text { Total dust }\left(\mathrm{mg} / \mathrm{m}^{\mathrm{s}}\right)\end{array}$} \\
\hline & Median & Mean & Range & $n$ & Median & Mean & $n$ \\
\hline \multicolumn{8}{|l|}{ Mill I } \\
\hline Seed feeder & - & - & & & $7 \cdot 4$ & $12 \cdot 6$ & 8 \\
\hline Cleaning room & $1 \cdot 8$ & $1 \cdot 9$ & $1 \cdot 3-2 \cdot 3$ & 5 & $1 \cdot 3$ & $1 \cdot 6$ & 9 \\
\hline Huller room & $1 \cdot 7$ & $1 \cdot 4$ & $0.4-3.7$ & 21 & $1 \cdot 3$ & 1.6 & 9 \\
\hline Lint room & 0.4 & 0.7 & $0 \cdot 2-3 \cdot 0$ & 32 & $1 \cdot 4$ & $1 \cdot 4$ & 7 \\
\hline Baler & - & - & & & $1 \cdot 2$ & $1 \cdot 4$ & 7 \\
\hline Shift foreman & - & - & & & 0.9 & 0.9 & 6 \\
\hline \multicolumn{8}{|l|}{ Mill II } \\
\hline Seed feeder & - & - & & & 0.9 & $2 \cdot 2$ & 5 \\
\hline Cleaning room & 0.6 & 0.7 & $0.5-1 \cdot 1$ & 5 & $3 \cdot 8$ & $3 \cdot 4$ & 8 \\
\hline Huller room & $1 \cdot 5$ & $1 \cdot 6$ & $0.5-1.8$ & 29 & $3 \cdot 8$ & $3 \cdot 4$ & 8 \\
\hline Lint room 1 & 0.8 & $1 \cdot 1$ & $0.4-3.5$ & 18 & $2 \cdot 2$ & $3 \cdot 6$ & 10 \\
\hline Lint room 2 & 0.8 & $1 \cdot 1$ & $0.4-3.5$ & 18 & 1.8 & $2 \cdot 0$ & 7 \\
\hline Saw filer & - & - & & & $2 \cdot 0$ & $2 \cdot 2$ & 3 \\
\hline Shift foreman & - & 一 & & & 0.8 & 0.9 & 8 \\
\hline \multicolumn{8}{|l|}{ Mill III } \\
\hline Seed feeder & - & - & & & $4 \cdot 1$ & $5 \cdot 2$ & 10 \\
\hline Cleaning room & $1 \cdot 5$ & $1 \cdot 8$ & $1 \cdot 2-3 \cdot 4$ & 12 & $6 \cdot 1$ & $5 \cdot \overline{7}$ & 9 \\
\hline Huller room & $2 \cdot 0$ & $2 \cdot 7$ & $0.9-10.0$ & 17 & $6 \cdot 1$ & $5 \cdot 7$ & 9 \\
\hline Lint room & 0.8 & 0.8 & $0 \cdot 3-1 \cdot 4$ & 30 & $1 \cdot 6$ & $1 \cdot 6$ & 5 \\
\hline Baler & $11 \cdot 3$ & $7 \cdot 6$ & $0 \cdot 8-15 \cdot 9$ & 10 & 4.9 & $5 \cdot 6$ & 19 \\
\hline Foreman & - & - & & & $1 \cdot 2$ & $1 \cdot 2$ & 3 \\
\hline Saw filing area & 0.3 & 0.4 & $0.2-0.8$ & 5 & - & - & \\
\hline Lint beating room & $4 \cdot 3$ & $4 \cdot 3$ & $4 \cdot 1-4 \cdot 6$ & 5 & - & - & \\
\hline \multicolumn{8}{|l|}{ Mill IV } \\
\hline Cleaning room & - & - & & & $1 \cdot 1$ & $1 \cdot 1$ & 8 \\
\hline Huller room & 0.6 & 0.7 & $0 \cdot 2-2 \cdot 1$ & 20 & 1.0 & $2 \cdot 0$ & 8 \\
\hline Lint room operator & - & - & & & 0.6 & 0.8 & 7 \\
\hline Lint room cleaner & 0.4 & 0.4 & $0 \cdot 1-1 \cdot 2$ & 19 & $3 \cdot 5$ & $5 \cdot 5$ & 6 \\
\hline Lint room & - & - & & & $1 \cdot 1$ & $1 \cdot 1$ & 3 \\
\hline Baler & - & - & & & $2 \cdot 2$ & 2.0 & 7 \\
\hline Hull sacker & - & - & & & $5 \cdot 8$ & $5 \cdot 9$ & 3 \\
\hline Cleaning-baling & 0.6 & 0.9 & $0 \cdot 1-4 \cdot 4$ & 28 & - & - & \\
\hline Saw filing & 0.3 & $0 \cdot 3$ & $0.1-0.4$ & 5 & - & - & \\
\hline Huller room 2 & 0.4 & 0.4 & $0.2-0.5$ & 15 & - & 一 & \\
\hline
\end{tabular}

of $300 \mathrm{ml}$ and the latter of $60 \mathrm{ml}$ in $\mathrm{FEV}_{1}$ over the working shift. A fourth individual fitted the definition for 'chronic byssinosis'. He was a 62year-old man who had worked in a foundry for 15 years and had a 'heart condition'. He was a smoker with only three years of work in the mill, in a job with intermediate dust exposure. His $\mathrm{FEV}_{1}$ was $99 \%$ of the predicted value, and his ventilatory function did not decline over the working shift. The prevalence of byssinosis in this group of workers is thus four of 172 , or $2 \cdot 3 \%$.

Seven of 172 participants had chronic bronchitis. This prevalence of $4 \%$ is lower than has been found for most working populations. The explanation may include both the relative youth of this population and the effects of geography and climate. When the definition of chronic bronchitis was relaxed to require only one or more years with productive cough of three months or more, only 24 participants $(14 \%)$ fit this definition. Forty-nine participants had 'dyspnoea', as defined above. This symptom, however, was not related to level of dust exposure, length of exposure, or smoking.

\section{LUNG FUNCTION STUDIES}

Baseline ventilatory function values, obtained from 158 subjects before work on Monday, are displayed as frequency distributions of percentages of predicted values in Figure 2. For each parameter, the probability of an individual having an observed value below $80 \%$ predicted was examined in the terms of the variables of level of exposure, length of exposure, and smoking. For the forced vital capacity (FVC), only three subjects had values less than $80 \%$ predicted; and only seven subjects had $\mathrm{FEV}_{1}$ values less than $80 \%$ predicted. These proportions were too small for statistical analysis of relationship to the influencing variables. For the $\mathrm{FEF}_{25^{-7}}, 66$ individuals $(42 \%)$ had values less than $80 \%$ predicted. On statistical analysis, the probability of having a subnormal $\mathrm{FEF}_{25-75}$ was found to depend upon smoking and lengthy dust exposure but not upon current level of exposure. 


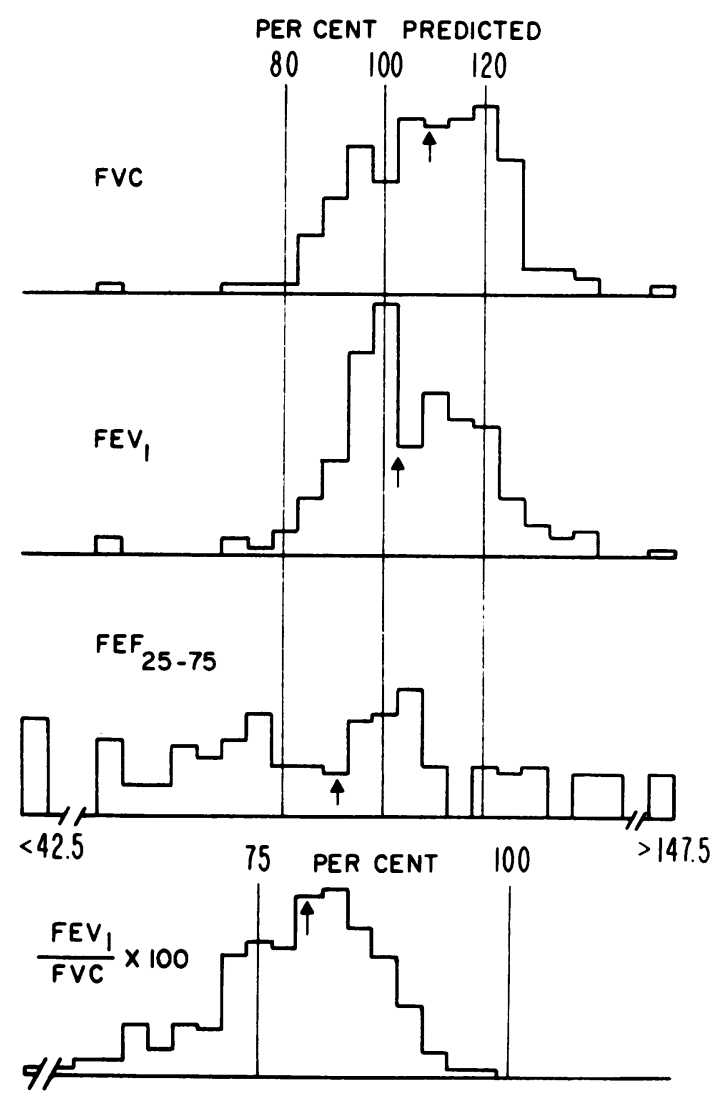

Fig. 2 Baseline ventilatory function (158 subjects).

The same was true of the ratio $\mathrm{FEV}_{1} / \mathrm{FVC} \times 100$ $\left(\mathrm{FEV}_{1} \%\right)$, where having a value of less than $75 \%$ depended on smoking and length of exposure but not on level of exposure. It must be acknowledged, however, that while we have treated length of exposure as a separate variable, it shows a strong correlation with age and, in smokers, with duration of smoking. It is thus possible that associations with lengthy dust exposure are actually observed because of ageing and prolonged use of tobacco.

Mean functional changes over the working shift were assessed in 153 workers who completed tests before and after work on Monday. These values are shown in Table 2, the negative signs indicating declines. Except for the negligible change in $\mathrm{FEV}_{1} \%$, all of the mean changes were significantly different from zero or no change. Twenty-one per cent of the population showed a decline in $\mathrm{FEV}_{1}$ of more than $150 \mathrm{ml}$, and $29 \%$ showed a decline in $\mathrm{FEF}_{25-75}$ of more than $0.41 / \mathrm{sec}$. Similar proportions had significant declines of maximum
Table 2 Mean lung function changes over the working shift (negative number indicates decline)

\begin{tabular}{|c|c|c|c|}
\hline \multirow[t]{2}{*}{ Test } & \multicolumn{2}{|l|}{ Monday $(n=153)$} & Friday $(n=145)$ \\
\hline & $\begin{array}{l}\text { Mean change } \\
( \pm S E)\end{array}$ & $\begin{array}{l}\% \text { with change } \\
\text { larger than } \\
\text { (level) }\end{array}$ & $\begin{array}{l}\text { Mean change } \\
( \pm S E)\end{array}$ \\
\hline FVC & $\begin{array}{l}-52 \mathrm{ml}^{*} \\
( \pm 13)\end{array}$ & & $\begin{array}{l}-27 \mathrm{ml} \\
( \pm 13)\end{array}$ \\
\hline FEV $_{1}$ & $\begin{array}{l}-48 \mathrm{ml}^{* *} \\
( \pm 14)\end{array}$ & $21(-150 \mathrm{ml})$ & $\begin{array}{l}6 \mathrm{ml} \\
( \pm 11)\end{array}$ \\
\hline $\mathrm{FEF}_{25-75}$ & $\begin{array}{l}-0.1731 / \mathrm{sec}^{* *} \\
( \pm 0.042)\end{array}$ & $29(-0.41 / \mathrm{sec})$ & $\begin{array}{l}-0.0351 / \mathrm{sec} \\
( \pm 0.038)\end{array}$ \\
\hline $\mathrm{FEV}_{1} \%$ & $\begin{array}{l}-0.3 \% \\
( \pm 0.2)\end{array}$ & & $\begin{array}{l}0.6 \% \\
( \pm 0.1)\end{array}$ \\
\hline$V_{\max } E_{50}$ & $\begin{array}{l}0.1021 / \mathrm{sec}^{*} \\
( \pm 0.051)\end{array}$ & $23(-0.61 / \mathrm{sec})$ & $\begin{array}{l}0.0191 / \mathrm{sec} \\
( \pm 0.051)\end{array}$ \\
\hline$V_{\max } E_{2 s}$ & $\begin{array}{l}-0.1361 / \sec ^{* *} \\
( \pm 0.033)\end{array}$ & $25(-0.351 / \mathrm{sec})$ & $\begin{array}{l}-0.0351 / \mathrm{sec} \\
( \pm 0.029)\end{array}$ \\
\hline
\end{tabular}

*Decline significantly $(\mathrm{P}<0.05)$ greater than zero.

**Decline significantly $(P<0.05)$ greater than zero and greater that decline over the Friday working shift.

expiratory flow at $50 \%\left(\mathrm{~V}_{\max } \mathrm{E}_{50}\right)$ and $25 \% \overrightarrow{\mathrm{g}}$ $\left(\mathrm{V}_{\mathrm{max}} \mathrm{E}_{25}\right)$ of FVC. For the $\mathrm{FEV}_{1}, \mathrm{FEF}_{25^{-75}}$, and maximum expiratory flow rate at $25 \%$ of $\mathrm{FVC}_{\odot}$ the observed mean decline was not only signifis cantly greater than zero but was significantly greater than the observed mean change over the working shift on Friday. These findings documen $\$$ an acute bronchoconstrictor effect in this popula $\overrightarrow{0}$ tion despite the low prevalence of byssinosis as defined by questionnaire response.

The probability of showing an excessive decline. in $\mathrm{FEV}_{1}$ or $\mathrm{FEF}_{25-75}$ did not, however, depend of smoking, length of exposure, or level of exposure This was also true of the maximum expiratory flowk at $50 \%$ of FVC. For the maximum expiratory flow at $25 \%$ of FVC there were paradoxical relation ships with smoking and length of exposure, ie excessive declines occurred significantly more often in non-smokers and in workers with short dust exposures.

\section{Discussion}

Recent studies in cotton textile mills have demon: strated biological effects with low exposure levels (Fox et al., 1973; Merchant et al., 1973; Berry ef al., 1974). Non-textile sources of cotton dust expoo sure have received, as stated above, little syste $\Phi$ matic study. Gilson et al. (1962) measured dust levels in several cotton ginneries in Uganda, and compared these with ventilatory changes over the Monday working shift. A substantial mean decline was documented in one ginnery. The fine duse concentration was 20 times that in a Ugandar textile mill, suggesting that the biological 'effec $\$$ is much less marked than in cotton mills'. Khoga廷 
(1969) recorded histories of chest tightness (after annual holiday) in $20 \%$ of ginnery and $48 \%$ of farfara workers in the Sudan. Two years later, Khogali (1976) found that the same workers showed a mean $\mathrm{FEV}_{1}$ increase; dust levels and prevalences of respiratory symptoms remained high. El Batawi (1962) found that symptoms of byssinosis were actually more prevalent in ginning $(38 \%)$ and bale pressing $(53 \%)$ than in carding $(27 \%)$, although the last operation had a higher proportion with grade II byssinosis. Ginning seemed safer in Greece, there being no cases of byssinosis in 70 workers evaluated by Kondakis and Pournaras (1965). There were no byssinotics in a study by Palmer et al. (1974) in the southwestern United States. Workers in the waste cotton industry were evaluated by DingwallFordyce and O'Sullivan (1966): 5\% had disabling byssinosis and $25 \%$ had byssinosis of milder grades. Cotton garnetting, the production of mattress stuffing from linters, cardroom waste, and waste cotton, was associated with total dust levels up to $21 \mathrm{mg} / \mathrm{m}^{3}$ in a study by Simpson (1970). The 26 workers in that study had a mean $F_{1} V_{1}$ postshift decline of $120 \mathrm{ml}$, a subgroup with the dustier jobs having a mean decline of $280 \mathrm{ml}$. There was no significant decline in those exposed to total dust levels of $6 \mathrm{mg} / \mathrm{m}^{3}$ or less, again suggesting less bioactivity than cardroom dust.

The health effects of exposure to dust in Australian cottonseed mills was examined by Barnes and Simpson (1968). The first mill studied used hydrochloric acid to remove linters and anhydrous ammonia to neutralise the acid. Total dust levels ranged from 7 to $32 \mathrm{mg} / \mathrm{m}^{3}$. Six of 11 subjects had work-related respiratory symptoms, but there was no case of byssinosis. A mean post-shift $\mathrm{FEV}_{1}$ decline of $300 \mathrm{ml}$ was observed. Simpson and Barnes (1968) later published a similar study in a mill using mechanical saws for delinting. Total dust levels of $15-37 \mathrm{mg} / \mathrm{m}^{3}$ were found. A $160 \mathrm{ml}$ mean decline of $\mathrm{FEV}_{1}$ occurred over the working shift in 16 exposed workers, compared to a $90 \mathrm{ml}$ increase for a group of 11 non-exposed workers. There was no mention of symptoms in this article.

Noweir et al. (1969) administered a questionnaire to workers in Egyptian cottonseed mills. The raw seed had been subjected to steam sterilisation before being shipped to the mill. Thirty-five of 110 workers exposed to cotton dust had work-related respiratory symptoms, but these became worse on each succeeding day in the working week, reaching a maximum on the sixth day.

The present study documents relatively high levels of resirable and total dust, and a low prevalence of byssinosis, in four cottonseed mills. Despite the low prevalence of symptoms, the study population showed an acute bronchoconstrictor response on Monday that was not present on Friday of the same week. This response provides evidence of bioactivity of the dust and indicates a need for reduction of current dust levels. The inability to relate post-shift functional declines to current exposure levels is due probably to difficulty in arriving at good estimates of individual exposures. The gravimetric samples may provide poor estimates of individual exposures because of crowding and overlapping of different milling operations, considerable worker movement during the shift, and lack of a personal monitor capable of sampling only respirable dust. Further, the composition and bioactivity of dust samples from different milling operations, and from mill to mill, may be expected to vary. In spite of this lack of precise data on individual exposures, the generally high respirable dust levels and low prevalence of byssinosis suggest that the overall dose-response relationship differs from that found in the cotton textile industry.

This study was supported in part by NHLI SCOR grant P 17 HL 15092-04. We gratefully acknowledge the assistance of the industrial hygienists and manufacturing staff of the Buckeye Crushing Division of the Procter and Gamble Company.

\section{References}

Barnes, R. and Simpson, G. R. (1968). Ventilatory changes on exposure to cotton dust. Medical Journal of Australia, 1, 897-900.

Berry, G., Molyneux, M. K. B., and Tombleson, J. B. L. (1974). Relationship between dust level and byssinosis and bronchitis in Lancashire cotton mills. British Journal of Industrial Medicine, 31, 18-27.

Dingwall-Fordyce, I. and O'Sullivan, J. G. (1966). Byssinosis in the waste cotton industry. British Journal of Industrial Medicine, 23, 53-57.

El Batawi, M. A. (1962). Byssinosis in the cotton industry of Egypt. British Journal of Industrial Medicine, 19, 126-130.

Fox, A. J., Tombleson, J. B. L., Watt, A., and Wilkie, A. G. (1973). A survey of respiratory disease in cotton operatives. Part II. Symptoms, dust estimations, and the effect of smoking habit. British Journal of Industrial Medicine, 30, 48-53.

Gilson, J. C., Stott, H., Hopwood, B. E. C., Roach, S. A., McKerrow, C. B., and Schilling, R. S. F. (1962). Byssinosis: the acute effect on ventilatory capacity of dusts in cotton ginneries, cotton, sisal, 
and jute mills. British Journal of Industrial Medicine, 19, 9-18.

Khogali, M. (1969). A population study in cotton ginnery workers in the Sudan. British Journal of Industrial Medicine, 26, 308-313.

Khogali, M. (1976). Byssinosis: a follow-up study of cotton ginnery workers in the Sudan. British Journal of Industrial Medicine, 33, 166-174.

Kondakis, X. G. and Pournaras, N. (1965). Byssinosis in cotton ginneries in Greece. British Journal of Industrial Medicine, 22, 291-294.

Merchant, J. A., Lumsden, J. C., Kilburn, K. H., O'Fallon, W. M., Ujda, J. R., Germino, V. H., and Hamilton, J. D. (1973). Dose response studies in cotton textile workers. Journal of Occupational Medicine, 15, 222-230.

Noweir, M. H., El-Sadek, Y., and El-Dakhakhny, A. A. (1969). Exposure to dust in the cotton- seed oil extraction industry. Archives of Environ mental Health, 19, 99-102.

Palmer, A., Finnegan, W., Herwitt, P., Waxweiler믐 R., and Jones, J. (1974). Prevalence of byssinosis in cotton gins in lower Rio Grande Valley of Texas and Messilla Valley of New Mexico. US Departmentw of Health, Education and Welfare (NIOSH) Cincinnati, Ohio.

Simpson, G. R. (1970). Exposure to dyst in the cotton= garnetting industry. Medical Journal of Australia 1, 1151-1152.

Simpson, G. R. and Barnes, R. (1968). Cotton dust exposure during lint removal. Archives of Environ $\mathrm{N}_{\mathrm{N}}$ mental Health, 17, 807-810.

Requests for reprints to: $\operatorname{Dr} R$. N. Jones, 1700 Peridido Street, New Orleans, Louisana, USA, 70112._ 